\title{
PERBEDAAN HASIL BELAJAR MANAJEMEN TERPADU BALITA SAKIT (MTBS) MELALUI MEDIA PEMBELAJARAN VISUAL DAN AUDIOVISUAL
}

\author{
Annif Munjidah \\ Fakultas Keperawatan dan Kebidanan \\ Universitas Nahdlatul Ulama Surabaya Jl. Smea 57 Surabaya \\ Email: annifmunjidah@unusa.ac.id
}

\begin{abstract}
Abstrack : Learning differences of integrated management of children sick (IMCI) Learning through Visual Media and Audiovisual. Integrated management of childhood illness is effective cost to solve toddler's death that is caused by acute respiratory infections, diarrhea, measles, malaria, and malnutrition The students of midwifery as candidate of midwife must have good ability in integrated management of childhood illness. The purpose of this research is analysis study result of integrated management of childhood illness of learning media visual and audiovisual for students of Midwifery Diploma Degree Department FKK of UNUSA. This research used experimental analytic design by quasi experimental design "after only with control quasi experimental". The populations were all students of Midwifery Diploma Degree, faculty of medical sains Nahdatul Ulama University Surabaya are 177 students. The sampling technique used simple random sampling technique. The total of sample is 60 respondents that were divided into 30 respondents in treatment group and 30 respondents in control group. Data analysis used independent $t$ test. There was the difference of study result statically significant between the students who got material by visual and audiovisual learning media. They who got material by audiovisual media had higher study result than those using visual media
\end{abstract}

\begin{abstract}
Abstrak: Perbedaan hasil belajar manajement terpadu balita sakit (MTBS) melalui media pembelajaran visual dan audiovisual. Manajemen Terpadu Balita Sakit (MTBS) merupakan cost effective untuk mengatasi masalah kematian balita yang disebabkan oleh infeksi Pernafasan Akut, diare, campak, malaria, dan kurang gizi. Mahasiswa kebidanan sebagai calon bidan harus memiliki kemampuan yang baik dalam manajemen terpadu balita sakit (MTBS). Tujuan dari penelitian ini adalah menganalisis perbedaan hasil belajar manajemen terpadu balita sakit (MTBS) melalui media pembelajaran visual dan audiovisual pada mahasiswa Prodi DIII Kebidanan FKK UNUSA.Penelitian ini menggunakan desain Analitik eksperimental dengan desain eksperimental quasi "after only with control quasi experimental design". Populasinya adalah seluruh mahasiswa Prodi DIII Kebidanan Fakultas Keperawatan Kebidanan Universitas Nahdlatul Ulama Surabaya sebesar 177 orang. Tehnik pengambilan sample menggunakan tehnik simple random sampling. Jumlah sampel sebesar 60 responden yang terbagi dengan 30 responden pada kelompok perlakuan dan 30 responden pada kelompok kontrol. Analisis data menggunakan uji independent t test dengan kemaknaan $p \leq 0,05$. Terdapat perbedaan hasil belajar secara statistik signifikan antara mahasiswa yang mendapat materi melalui media pembelajaran visual dengan audiovisual. Mahasiswa yang mendapat materi melalui media audiovisual rata-rata memiliki hasil belajar yang lebih tinggi dibanding dengan media visual
\end{abstract}

Kata Kunci: visual, audiovisual, Media pembelajaran, hasil Belajar 


\section{PENDAHULUAN}

Bank Dunia tahun 1993 melaporkan bahwa Manajemen Terpadu Balita Sakit (MTBS) merupakan cost effective untuk mengatasi masalah kematian balita yang disebabkan oleh infeksi pernafasan akut (ISPA), diare, campak, malaria, dan kurang gizi. WHO dan UNICEF memperkenalkan MTBS melalui Departemen Kesehatan RI dan UKKIDAI. (Depkes RI: 2011)

MTBS digunakan sebagai standar pelayanan sekaligus sebagai pedoman bagi tenaga kesehatan (bidan dan perawat) khususnya di fasilitas pelayanan kesehatan dasar. Penerapan MTBS akan efektif jika ibu atau keluarga segera membawa balita sakit ke petugas kesehatan yang terlatih sehingga dengan cepat dapat ditentukan pengobatannya (Depkes RI: 2011). Namun dalam prakteknya manajemen terpadu balita sakit ini masih mengalami hambatan yang salah satunya dikarenakan keterampilan petugas.

Hasil penelitian MTBS oleh Djoko Mardijanto dan Mubasyir Hasan Basri tahun 2005 di Jawa Tengah menunjukkan bahwa sudah ada perbaikan dalam pengobatan anak sakit melalui manajemen terpadu balita sakit oleh tenaga kesehatan namun kemampuan petugas kesehatan dalam mengikuti klasifikasi kondisi anak dan melakukan pencatatan seperti yang diharapkan masih kurang.

Sesuai kurikulum DIII Kebidanan MTBS termasuk salah satu pokok bahasan dalam mata kuliah Asuhan Neonatus, Bayi, Balita dan Anak (ANBB) dengan jumlah SKS 5 (T:3, P:2) di semester III. Dalam proses pembelajarannya mahasiswa sebagai calon tenaga kesehatan harus mampu menilai dan membuat klasifikasi, menentukan tindakan, memberi pengobatan, memberi konseling bagi ibu, tata laksana dan pelayanan tindak lanjut.

Berdasarkan observasi pendahuluan di Prodi DIII Kebidanan Fakultas Keperawatan Kebidanan Universitas Nahdlatul Ulama Surabaya tahun 2014 pembelajaran di kelas, pengajar hanya menggunakan media bantu berupa buku foto, bagan dinding, formulir dinding dan slide power point, meskipun telah ada video MTBS dari WHO yang berisikan materi tentang penilaian tanda bahaya umum maupun pengkajian fisik lainnya. Setelah dilakukan analisis butir didapatkan nilai sebagai berikut di bawah ini.

Tabel 1. Nilai butir soal MTBS

\begin{tabular}{ccc}
\hline Nilai & $\begin{array}{c}\text { Jumlah } \\
\text { Mahasiswa }\end{array}$ & $\begin{array}{c}\text { Persentase } \\
(\%)\end{array}$ \\
\hline$\geq 75$ & 15 & 8,0 \\
$70-$ & 79 & 42,0 \\
74,9 & & \\
$65-$ & 71 & 37,7 \\
69,9 & & \\
$60-$ & 15 & 8,0 \\
64,9 & & \\
$\leq 59,9$ & 8 & 4,2 \\
Total & 188 & 100 \\
\hline
\end{tabular}

Sumber: Data Sekunder Tahun 2014

Dari tabel 1 diatas dapat disimpulkan bahwa sebanyak 23 mahasiswa $(12,2 \%)$ masih memiliki nilai $<65$, yang berarti hasil belajar mahasiswa secara kognitif masih kurang.

Menurut Sri Esti. W.D (2002) dengan mengetahui hasil belajar siswa seorang guru dapat mengetahui apakah dia sudah berhasil ataukah gagal dalam memberikan pelajaran pada siswa. Pengetahuan akan kegagalannya akan memberikan tantangan dalam memperbaiki misalnya dengan mengubah metode, sistematika bahan, media maupun sikapnya.

Hasil belajar menjadi tolak ukur dalam keberhasilan proses belajar mengajar (Moedjiarto: 2007). Hal ini tidak terlepas dari dari faktor-faktor yang dapat mempengaruhi keberhasilan belajar seperti minat, motivasi, lingkungan belajar, fasilitas/sarana prasarana dan guru (Santrock, 2011)

Menurut Edgar Dale dalam Dimyati Mujiono (2013) mengemukakan bahwa kegiatan pembelajaran yaitu pengalaman langsung, pengalaman yang diatur, dramatisasi, demonstrasi, karyawisata, pameran, televisi, dan film sebagai alat 
peraga. Televisi dan alat peraga tersebut merupakan hasil dari pengembangan teknologi yang digunakan dalam kegiatan pembelajaran yaitu melalui pengembangan media. Hal ini merupakan suatu langkah nyata untuk mengadakan perubahan dalam proses transfer informasi. Menurut Sagala (2009) pembelajaran dengan media berarti mengalihkan posisi seorang guru sebagai sumber informasi utama menjadi fasilitator untuk siswa, hal tersebut juga didukung oleh Thalib (2010) bahwa penggunaan media akan membuat pembelajaran lebih efektif dalam penyampaian informasi. Hasil penelitian yang telah dilakukan oleh Pera Nurfathiyah dan Tri suratno (2012) menunjukkan pengaruh penyajian pesan dengan menggunakan visualisasi gerak lebih efektif daripada visualisasi foto

Dari latar belakang yang telah disebutkan di atas maka peneliti tertarik untuk melakukan penelitian mengenai "Perbedaan hasil belajar manajemen terpadu balita sakit melalui media pembelajaran visual dan audiovisual pada mahasiswa Prodi DIII Kebidanan Fakultas Keperawatan Kebidanan Universitas Nahdlatul Ulama Surabaya"

\section{METODE}

Jenis penelitian Analitik eksperimental dengan desain eksperimental quasi "after only with control quasi experimental design". Populasi dalam penelitian ini adalah seluruh mahasiswa Prodi DIII Kebidanan Fakultas Keperawatan Kebidanan Universitas Nahdlatul Ulama Surabaya sebesar 177 orang. Sampel dalam penelitian ini adalah Sebagian mahasiswa semester III Prodi DIII Kebidanan yang terbagi menjadi dua kelompok. Yaitu kelompok kelas A, B yang mendapat perlakuan pembelajaran menggunakan media audiovisual. Kelompok Kelas C, D yang mendapat perlakuan pembelajaran menggunakan media visual. Besar sampel dalam penelitian ini adalah sebagian mahasiswa Prodi DIII Kebidanan dengan kelompok perlakuan media audiovisual (kelas A, B) sebesar 30 orang. Kelompok perlakuan media visual (kelas C, D) sebesar 30 orang. Tehnik pengambilan sample dalam penelitian ini adalah simple random sampling. Pelaksanaan penelitian ini dilakukan di Prodi DIII Kebidanan FKK Unusa. Sedangkan Waktu pelaksanaannya dilakukan pada bulan September 2015 s.d Desember 2015.

Instrumen pada variabel ini berupa soal yang bertipe multiplechoice. Responden dapat memberi tanda silang (X) pada jawaban yang dianggap paling benar setelah mendapatkan pembelajaran. Analisis statistik dengan uji $\mathrm{t}$

\section{HASIL DAN PEMBAHASAN}

Penelitian ini telah dilakukan pada mahasiswa semester III Program studi DIII Kebidanan Fakultas Keperawatan Kebidanan (FKK) Universitas Nahdlatul Ulama Surabaya (UNUSA) yang beralamat di Jl. Smea No: 57 Surabaya. UNUSA merupakan pengembangan dari Stikes Yarsis melalui ijin pendirian Universitas oleh Dirjen Dikti pada tanggal 02 Juli 2013. Dalam perijinan tersebut terdiri dari lima Fakultas dan 16 Program Studi yang salah satunya yaitu prodi DIII Kebidanan.

Mulai tahun Tahun Akademik 2013/2014 Prodi DIII Kebidanan program studi DIII Kebidanan Unusa telah menggunakan kurikulum berbasis kompetensi (KBK) yang berpedoman pada kurikulum nasional

Pengambilan data pada variabel hasil belajar dengan evaluasi berupa soal pilihan ganda dan variabel media pembelajaran dengan pengelompokan menjadi kelompok media visual dan media audiovisual. Kuesioner yang digunakan telah dilakukan uji validitas dan reliabilitas. Pengujian instrumen dilakukan pada 15 responden. Jumlah sampel dalam penelitian sebanyak 60 mahasiswa yang memenuhi kriteria dengan teknik simple random sampling. 


\section{a.Hasil Penelitian}

Perbedaan hasil belajar melalui media visual dan audiovisual

Tabel 2. Perbedaan hasil belajar melalui media pembelajaran visual dan audiovisual

\begin{tabular}{cccccc}
\hline Kelp. & $\mathrm{N}$ & Mean & $\mathrm{SD}$ & $\begin{array}{c}\mathrm{t} \\
\text { independen }\end{array}$ & $\mathrm{P}$ \\
\hline $\begin{array}{c}\text { audiovisual } \\
\text { visual }\end{array}$ & 30 & 80.0 & 12.9 & 2,033 & 0,047 \\
\hline
\end{tabular}

Sumber : Data primer tahun 2015

Tabel 2. diatas menunjukkan bahwa beda mean hasil belajar manajemen terpadu balita sakit setelah mendapatkan materi melalui penggunaan media antara 2 kelompok, mean berbeda secara bermakna karena lebih tinggi pada kelompok yang mendapatkan pembelajaran melalui media audiovisual dibanding dengan visual. Dilihat dari nilai $\mathrm{p}$ sebesar 0,047. Dengan demikian nilai $\mathrm{p}$ lebih kecil dari nilai $\alpha$ $(0,05)$ artinya ada perbedaan pengaruh media pelajaran dengan hasil belajar

\section{b. Pembahasan}

Hasil analisis independent sample t test yang ada pada tabel 2 didapatkan nilai mean media audiovisual 80, mean media visual 72,50 dengan nilai $t$ independen 2,033 sedangkan nilai $\mathrm{P}=0,047$ lebih kecil dari nilai $\alpha(0,05)$ artinya ada perbedaan pengaruh media pelajaran dengan hasil belajar. Beda mean hasil belajar manajemen terpadu balita sakit setelah mendapatkan materi melalui penggunaan media antara 2 kelompok, mean berbeda secara bermakna karena lebih tinggi pada kelompok yang mendapatkan pembelajaran melalui media audiovisual dibanding dengan visual.

Penjabaran hasil diatas menunjukkan terdapat korelasi media pembelajaran terhadap hasil belajar, bahwa rata-rata hasil belajar mahasiswa tentang manajemen terpadu balita sakit menggunakan media pembelajaran audiovisual lebih baik dibanding visual. Hal ini sesuai dengan hipotesis penelitian yaitu media pembelajaran audiovisual lebih baik daripada media visual.

Hal ini sejalan dengan Oemar Hamalik (2010) bahwa semakin banyak alat indera yang digunakan untuk menerima dan mengolah informasi semakin besar kemungkinan informasi tersebut dimengerti dan dapat dipertahankan dalam ingatan sehingga proses belajar mengajar dapat berhasil dengan baik. Begitu juga dengan pendapat Paivio (1978) melalui konsep dual coding hypotesis (hipotesis koding ganda) menyebutkan bahwa belajar dengan menggunakan indera ganda yaitu pandang dan dengar akan memberikan keuntungan bagi siswa. Siswa akan belajar lebih banyak daripada jika materi pelajaran disajikan hanya dengan stimulus pandang atau hanya dengan stimulus dengar. Demikian halnya dengan hasil penelitian Asri yuni (2009) yang mengemukakan bahwa ada pengaruh penggunaan media pembelajaran video terhadap hasil belajar keterampilan memasang infus pada mahasiswa S1 Keperawatan Sekolah Tinggi Ilmu Kesehatan Kendedes Malang dan penelitian dari Fansuri hamzah (2013) bahwa penerapan video pembelajaran dapat meningkatkan prestasi belajar Siswa di SMKN 1 Sayegan.

Menurut Djamarah (2011) media adalah perantara atau pengantar pesan dari pengirim kepada penerima pesan. Dalam pembelajaran peran media sebagai alat untuk menangkap, memproses, dan menyusun kembali informasi visual atau verbal. Beberapa hal yang dapat mempengaruhi hasil belajar selain media yaitu faktor lingkungan kondisi fisiologis dan psikologis peserta didik antara lain: minat, kecerdasan, motivasi belajar, kemampuan kognitif.

Pada pembelajaran manajemen terpadu balita sakit mahasiswa dibekali teori tentang pengkajian fisik, dimana mahasiswa selain harus menguasai teori tentang pengkajian fisik juga dituntut untuk terampil dalam menggali data subyektif melalui anamnesa pada ibu dan keluarga. Berbeda dengan pasien dewasa 
pada umumnya, yang dapat menyampaikan keluhan yang dirasakan, pada pasien anak, petugas harus lebih jeli dalam menggali informasi dari ibu. Untuk itu melalui pembelajaran audiovisual pada MTBS ini mahasiswa diberikan gambaran nyata bagaimana cara melakukan pengkajian fisik dan anamnesa pada anak balita.

Pemaparan materi pada video MTBS akan memberi gambaran secara jelas sekaligus memberi pengalaman yang berbeda, mahasiswa akan mendapat gambaran secara nyata dibandingkan saat dosen menggunakan media visual pada saat pembelajaran. Terlebih pada materi MTBS ini mahasiswa harus mampu membedakan kondisi fisiologi dan patologi agar tepat dalam melakukan klasifikasi. Hal tersebut sesuai dengan teori Sadiman (2013) bahwa menghadirkan suasana nyata dalam pembelajaran akan sangat membantu mahasiswa dalam memahami materi perkuliahan, semakin banyak alat indera yang terlibat akan semakin mempermudah daya ingat, sehingga akan berdampak positif terhadap hasil belajar

\section{SIMPULAN}

1. Mahasiswa yang menggunakan media audiovisual pada manajemen terpadu balita sakit rata-rata memiliki hasil belajar sebesar 80,0

2. Mahasiswa yang menggunakan media visual pada manajemen terpadu balita sakit rata-rata memiliki hasil belajar sebesar 72,5

3. Terdapat perbedaan hasil belajar manajemen terpadu balita sakit secara statistik signifikan antara mahasiswa yang mendapat materi melalui media pembelajaran audiovisual dengan visual. Mahasiswa yang mendapat materi pembelajaran manajemen terpadu balita sakit melalui media audiovisual rata-rata memiliki nilai hasil belajar yang lebih tinggi dibanding yang mendapatkan materi melalui media visual

\section{DAFTAR RUJUKAN}

Depkes R.I. 2011. Buku Pedoman Manajemen Terpadu Balita Sakit (MTBS). Dinkes Provinsi: Jawa Timur

Djamarah, SB. 2011. Strategi belajar mengajar. Jakarta: PT. Rineka Cipta

Esti, Sri. WD. 2002. Psikologi pendidikan. Jakarta: Gramedia Widiasarana Indonesia

Hamalik, Oemar 2010 Media Pendidikan. (Cetakan ke-7). Bandung: penerbit PT Citra Aditya Bakti

Hamzah, Fansuri. 2013. Penerapan Video Pembelajaran Untuk Meningkatkan Prestasi Belajar Siswa Kelas X Fabrikasi Logam Pada Mata Pelajaran Teori Las Oxy-Acetylene Di SMK Negeri 1 SEYEGAN.

Mardijanto, Djoko dan Hasan, Mubasyir Basri. 2005. Jurnal Evaluasi MTBS Di kabupaten Pekalongan. Jurnal Manajemen Pelayanan Kesehatan 2005, VIII(1)

Moedjiarto. 2007 "Strategi Belajar Mengajar". Surabaya: University Surabaya press

Mujiono, Dimyati. 2013. Belajar dan Pembelajaran. Cetakan ke-5. Jakarta: PT: Rineka Cipta

Nurfathiyah, Pera dan Suratno Tri. 2011 Pengaruh Visualisasi Gerak dan Foto PadaMedia Video Terhadap peningkatan Pengetahuan Petani Di Desa Tangkit

Paivio, A. 1978. "A Dual Coding Approach to perception and Cognition”. In Pick,

Sadiman, A.S., Rahardjo, R., Haryono, A., dan Rahardjito. 2013. Media pendidikan pengertian, pengembangan dan pemanfaatan. Jakarta: PT. Raja Grafindo 
Sagala, S. 2009. Kemampuan Profesional Guru dan Tenaga Kependidikan. Bandung: alfabeta

Santrock, WJ. 2011. Psikologi Pendidikan: educational Psychologi. Edisi III Buku II. Jakarta: Salemba Humanika

Thalib, SB. 2010. Psikologi Pendidikan Berbasis Analisis Empiris
Aplikatif. Jakarta: Kencana Prenada Media Group

Yuni, Asri. 2009. "Pengaruh Pengaruh penggunaan media pembelajaran video dan gaya belajar mahasiswa terhadap hasil belajar ketrampilan memasang infus pada mahasiswa SlKeperawatan". Tesis Tidak dipublikasikan. UNS. Surakarta 